\title{
BLB: A Persuasive and Interactive Installation Designed to Improve Well-Being
}

\author{
Connie Golsteijn, Elise van den Hoven, Sijme Geurts, Max Eichenbrenner, \\ Christ van Leest, Sanne van den Hurk, and Yih Shun Ling \\ Industrial Design Department, Eindhoven University of Technology \\ P.O. Box 513, 5600 MB Eindhoven, The Netherlands \\ e.v.d.hovena.tue.nl
}

\begin{abstract}
Well-being is a broad subject, which is described in this paper as: a personal balance of mental, social and physical being, influenced by life circumstances and life factors. These factors include emotions, engagement, life satisfaction, intentional activities and social network. The project described in this paper aims at improving well-being through the design of a persuasive and interactive installation for the home environment. After the investigation of well-being by means of a literature study, cultural probes and questionnaires, a concept was developed. This paper describes the design, implementation and evaluation of this concept. 'BLB', as it is called, encourages its users to seize the moment in order to increase their well-being.
\end{abstract}

Keywords: well-being, persuasive technology, intentional activities, interaction design, human-computer interaction.

\section{Introduction}

Well-being reflects how people rate the quality of their lives. Studies have proposed ways to improve well-being, for example doing regular exercises or looking at events optimistically [1]. However, the development of a consumer product implementing these activities to increase well-being has surprisingly remained unexplored. To fill this gap, a project was started with the goal to design a product that could help people to structurally and effectively work on their well-being. This was done through a design research approach - an approach combining product design and scientific research by starting the design from literature.

The choice was made to design for intentional activities within the field of wellbeing, and more specifically for 'seizing the moment'. Seizing the moment is explained as: unplanned self-performed actions that instantly increase well-being, with a lasting effect [1]. Hence the design goal was to design a product which helps singles, the target group, to consciously and intentionally seize the moment in order to increase their well-being. This will be done directly and indirectly by increasing their awareness of what makes them happy.

\section{Idea Generation and Concept Development}

For the idea generation and selection phase we used three germinal ideation methods, suitable when there are no existing solutions: classical brainstorming, mapping subtopics 
around a main topic; morphological analysis, for exploring solutions to a multidimensional problem; and KJ-method, to cluster aspects of a problem. The first two methods were used to produce ideas and the third to categorize and reflect on solutions. Found categories were: building up, reflection and advice. The use of forced-relations, to combine unrelated topics into an idea, and brain writing resulted in a total of more than one hundred ideas. To select the ideas, fifteen criteria were formulated based on literature studies, cultural probes and questionnaires [2]. These criteria addressed well-being, intentional activities, and seizing the moment. During the selection process, visualized in Figure 1, six remaining ideas were shown to four test persons of the target group. They were asked if they understood the purpose of the idea, if they would use it and if they thought it would increase their well-being.

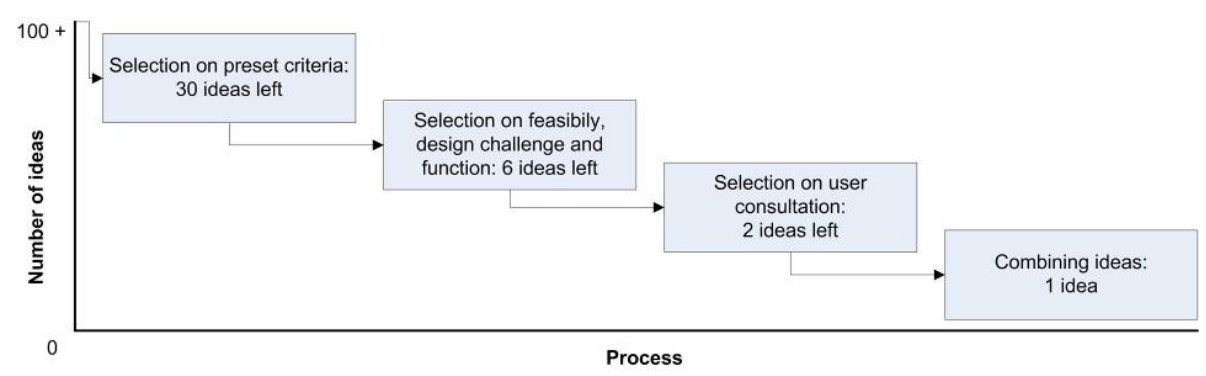

Fig. 1. A scheme of the idea selection process

This resulted in two ideas, the first is a practical advice clock, which gives a person feedback about ways to seize the moment and alerts him when friends are seizing the moment. The second idea, called 'wall bulbs', is an installation on a person's wall, meant to increase reflection. Both ideas interested the test group, so they were combined into a concept called BLB (pronounced as 'bulb').

BLB is an interactive installation used in-home. The bulbs resemble round containers in which users can place small artifacts or souvenirs. This placement can remind them of a location, person or activity that increased his or her well-being in the past and encourages reflection and/or action on that moment, potentially increasing wellbeing again. The installation consists of three types of bulbs: personal, shared and receive bulbs (see Figure 2). Personal bulbs are meant to support a goal or memory for the owner alone. Placing an artifact in the bulb or touching it will activate lights in and around the bulb (see Figure 2a). These lights will fade slowly over time. The light intensities of the personal bulbs display activities a user plans to do and activities he did. Another bulb-type is the shared bulb (see Figure 2b). This type has the same functionality as the personal bulb, but it is meant for activities or goals a person wants to share with his friends. The receive bulb (see Figure 2c) contains a display showing the picture of the artifact in a friend's shared bulb. All in all, BLB is intended to work as a personal encouragement to plan, reflect, and work on activities that increase a person's well-being, by seizing the moment. BLB can also provide inspiration for new activities through communication with friends, using and perhaps even strengthening existing social networks. 


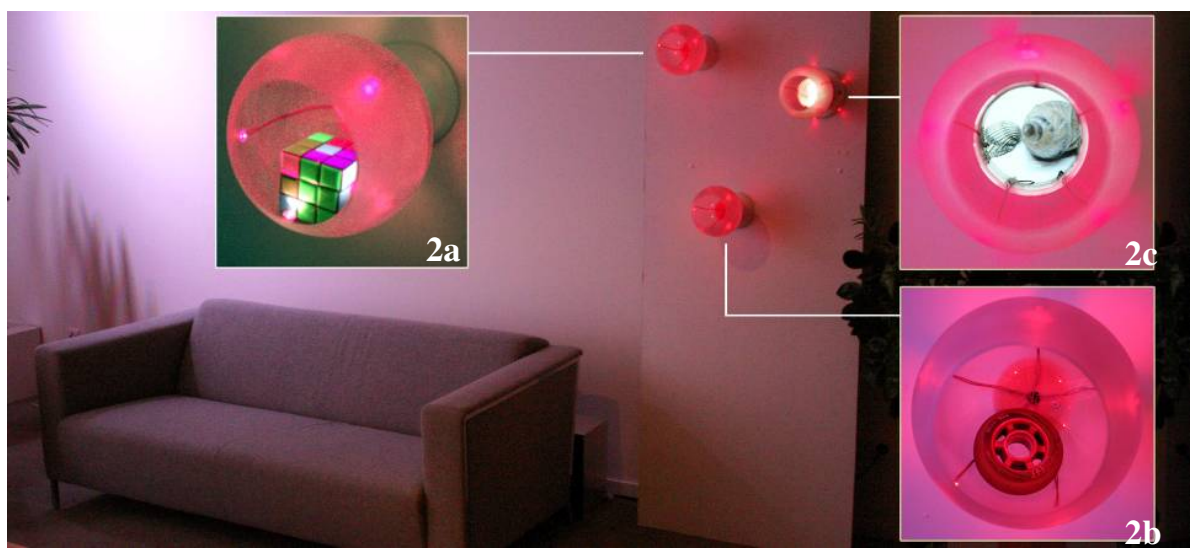

Fig. 2. BLB consists of bulbs placed on a wall, the personal bulb (2a), the shared bulb (2b), and the receive bulb (2c)

\section{Implementation}

BLB was implemented in a working demonstrator, see Figure 2. The bulbs consisted of sandblasted plastic spheres and wooden pedestals, the latter having integrated light buttons. Five LEDs were placed inside each bulb and five around its pedestal for feedback purposes. The personal bulb prototype was fully functional; it contained a button with which users could indicate that they had worked on an activity. After activation the LEDs faded slowly over time, which was programmed with Max/MSP using a Phidget interface. The shared and receive bulbs were partially functional. Communication between the two installations was done manually by the observers using a web server, while the LEDs worked the same as for the personal bulb.

Two walls with three bulbs each were implemented, in order to test two friends simultaneously in two different locations while using BLB.

\section{User Evaluation}

BLB was tested at the Homelab facility of the Philips Research Laboratories Eindhoven. In total there were 17 participants in the user evaluation (nine men, aged 34 on average and eight women, aged 29 on average), of which four were singles. Each test involved two separated participants, communicating trough the two BLB installations. One session took one hour, during which the users had to share artifacts with a friend and once they had to keep an artifact personal, ending the session with a semistructured interview. The intentions of the user evaluation were to find out: 1) if BLB increased people's awareness of the things that make them happy, 2) if BLB encouraged the user to seize the moment, and 3) if the installation could contribute to the user's general well-being. The results can be found in Table 1. Interesting suggestions that came forward were to use BLB for autistic children, as reminder for activities, or for the elderly, as memory for good moments of the past. 
Table 1. Results of the user evaluations of BLB, as user responses to the questions

\begin{tabular}{|l|c|c|c|}
\hline Questions & Negative & Neutral & Positive \\
\hline 1: Increases awareness of happiness & $29 \%$ & $18 \%$ & $53 \%$ \\
\hline 2: Encourages to seize the moment & $29 \%$ & $18 \%$ & $53 \%$ \\
\hline 3: Contributes to well-being in general & $0 \%$ & $35 \%$ & $65 \%$ \\
\hline
\end{tabular}

\section{Discussion and Conclusions}

Measuring well-being is difficult in a short project, because it is affected in long terms. Of course we had to make some assumptions, for example that the awareness of well-being and the execution of 'seizing-the-moment' activities are related and how they are related. Another assumption we made is that physical artifacts remind people of activities and intentions that are related to seizing the moment, instead of just the functions of the artifacts and related memories.

We concluded that the user evaluations of our concept called BLB gave a cautious but affirmative answer to the question whether BLB succeeded in facilitating and supporting people to work on and increase their well-being. Therefore BLB can be seen as one of the first products designed specifically for the increase of personal well-being, which opens up possibilities for the design of interactive, persuasive installations aiming at a broad and new topic, such as well-being.

\section{Acknowledgements}

We want to thank all participants in this study; Willem Fontijn and Jettie Hoonhout, Philips Research; and Peter Golsteijn.

\section{References}

1. Huppert, F.A., Baylis, N., Keverne, B. (eds.): The science of well-being. Oxford University Press, New York (2005)

2. van den Hoven, E., Golsteijn, C., Geurts, S., Eichenbrenner, M., van Leest, C., van den Hurk, S., Ling, Y.S.: Analyzing Well-being for the Design of a Persuasive \& Interactive Installation. In: CHI 2008-workshop: Surrounded by Persuasive Ambient Intelligence (accepted) 